\title{
Dialética do Fatalismo: do Fatalismo dos Indivíduos para o da Ordem
}

\author{
Pedro Henrique Antunes da Costa* \\ Universidade de Brasília - UnB, Brasília, DF, Brasil \\ ORCID: https://orcid.org/0000-0003-2404-8888 \\ Kíssila Teixeira Mendes** \\ Universidade Federal de Juiz de Fora - UFJF, Juiz de Fora, MG, Brasil \\ ORCID: https://orcid.org/0000-0002-7817-599X
}

\begin{abstract}
RESUMO
O presente trabalho objetiva realizar um resgate crítico do conceito de fatalismo cunhado por Martín-Baró, à luz da realidade brasileira. Nesse processo, explicitaremos sua natureza dialética, a partir dos movimentos de resignação e revolta, em perspectivas individuais e/ou coletivas. Trata-se de uma pesquisa teórica, cuja discussão fundamentou-se nas formulações e trabalhos do autor, em literatura secundária sobre o conceito, produções acerca do processo de formação brasileiro e, nele, contextos de pobreza e exploração econômico-política, bem como dados sobre nossa realidade e manifestações artísticas nacionais ilustrativas. Para além da faceta de resignação do fatalismo, apontada por Martín-Baró, destacamos sua relação dialética com a revolta e entre possibilidades individuais e coletivas. Assim, como transformar o fatalismo dos indivíduos em direção a perspectivas de revolta capazes de provocar rupturas estruturais nessa sociabilidade? E como a Psicologia brasileira pode contribuir para isso? As possibilidades de passagem de um fatalismo dos indivíduos para o da ordem, a partir da práxis do psicólogo brasileiro ou enquanto visão de mundo geral, são: (1) recuperação da memória histórica; (2) fortalecer a organização popular; (3) compreender-se e atuar enquanto classe trabalhadora; (4) fortalecer as condições objetivas comunitárias e (5) conscientização enquanto horizonte da Psicologia.
\end{abstract}

Palavras-chave: pobreza, subjetividade, dialética, psicologia, América Latina.

\section{Fatalism Dialectics: from the Fatalism of Individuals to that of the Order}

\begin{abstract}
This work aims to carry out a critical rescue of the concept of fatalism of Martín-Baró, in the light of the Brazilian reality. In this process, we will make its dialectical nature explicit, from the movements of resignation and revolt, in individual and/or collective perspectives. It is a theoretical research, whose discussion was based on the author's formulations, on secondary literature about the concept, productions about the Brazilian formation process and, in it, contexts of poverty and economic-political exploitation, as well as data about our reality and illustrative national artistic manifestations. In addition to the facet of resignation of fatalism, pointed out by Martín-Baró, we highlight its dialectical relationship with the revolt and
\end{abstract}

\begin{tabular}{|l|l|l|l|l|l|}
\hline Estudos e Pesquisas em Psicologia & Rio de Janeiro & v. 20 & n. 2 & p. $682-702$ & $\begin{array}{c}\text { Maio a Agosto } \\
\text { de } 2020\end{array}$ \\
\hline
\end{tabular}


between individual and collective possibilities. So, how to transform the fatalism of individuals towards perspectives of revolt capable of causing structural ruptures in this sociability? And how can Brazilian Psychology contribute to this? The possibilities of passing from a fatalism of individuals to that of order, based on the praxis of Brazilian psychologists or as a general worldview, are: (1) recovery of historical memory; (2) strengthen the popular organization; (3) the understanding and acting as a working class; (4) strengthen objective community conditions and (5) conscientization as a horizon of Psychology.

Keywords: poverty, subjectivity, dialectics, psychology, Latin America.

\section{Dialéctica del Fatalismo: del Fatalismo de los Individuos para el del Orden}

\section{RESUMEN}

El presente trabajo pretende realizar un rescate crítico del concepto de fatalismo de MartínBaró, a la luz de la realidad brasileña. En este proceso, haremos explícita su naturaleza dialéctica, desde los movimientos de resignación y revuelta, en perspectivas individuales y/o colectivas. Es una investigación teórica, cuya discusión se basó en las formulaciones del autor, en literatura secundaria sobre el concepto, producciones sobre el proceso de formación brasileño y, en él, contextos de pobreza y explotación económico-política, así como en datos sobre nuestra realidad y manifestaciones artísticas nacionales ilustrativas. Además de la faceta de la resignación del fatalismo señalada por Martín-Baró, destacamos su relación dialéctica con la revuelta y entre las posibilidades individuales y colectivas. Entonces, ¿cómo transformar el fatalismo de los individuos hacia perspectivas de revuelta capaces de causar rupturas estructurales en esta sociabilidad? ¿Y cómo puede contribuir la psicología brasileña? Las posibilidades de pasar del fatalismo de los individuos al orden, desde la praxis del psicólogo o como una cosmovisión general, son: (1) recuperación de la memoria histórica; (2) fortalecer la organización popular; (3) entender y actuar como clase trabajadora; (4) fortalecer las condiciones objetivas de la comunidad y (5) la conciencia como horizonte de la psicología.

Palabras clave: pobreza, subjetividad, dialéctica, psicología, América Latina.

O contexto latino-americano é ilustrativo da pobreza e da perpetuação da concentração de riquezas. Essa realidade díspar se dá pelo antagonismo de classes capitalista conformado em nossa constituição periférica, resultante de um processo de colonização, assentado em regimes escravocratas que perduram concreta e simbolicamente até os dias atuais. No Brasil o processo de desenvolvimento de nosso capitalismo tardio e modernização conservadora acentuaram a fragmentação social e desigualdade com o crescimento de centros urbanos, com as parcelas mais pobres da classe trabalhadora responsabilizadas pelos problemas do país e a pobreza tida como fruto da mestiçagem, do clima tropical e da desorganização social, e não 
uma expressão, nas especificidades formativas brasileiras coloniais, da própria natureza desigual e contraditória do capitalismo (Ribeiro, 2006).

Com o avanço de ideários neoliberais nos anos 1990, esse conjunto de antagonismos e condições de exploração e opressão que se expressam de maneira mais nevrálgica na pobreza, continuou a ser encarado como natural, minimizando ou desconsiderando debates estruturais, e tendo como uma de suas principais consequências o deslocamento do enfrentamento da questão do Estado para a esfera da filantropia e para iniciativas individuais. Tal realidade contribui ainda mais para o aprofundamento da miséria, do desemprego e das relações precarizadas de trabalho inerentes à sociabilidade capitalista (Yamamoto \& Oliveira, 2010).

Cabe ressaltar que a doutrina liberal influencia também a formação do pensamento social brasileiro, com muitos dos discursos, apesar de se dizerem voltados para a redução das desigualdades sociais, contribuindo para a sua naturalização. Se faz urgente, dessa forma, teorias que partam da realidade e se voltem para ela, num intuito não só de compreendê-la, mas de serem aporte para a sua transformação.

A partir dessas constatações, surge a pergunta: Por que os indivíduos, enquanto seres sociais, assumem tal posição diante da vida? Essa questão é cara à Psicologia, o que, por sua vez, pode se tornar ardiloso, visto que as explicações oriundas dessa área historicamente enfatizaram fatores individuais, em categorias rígidas e estáticas, como os conceitos de caráter e personalidade.

É dessa forma que nos parece que as formulações de Martín-Baró acerca do fatalismo latino-americano podem nos fornecer importantes subsídios teórico-práticos para o entendimento e mudança de nossa realidade. O fatalismo é definido por Martin-Baró (2017a) como um conformismo que se relaciona com a ideia de um destino fatal. Não se trata de um destino fatal em si, mas de uma posição derivada das relações sociais existentes e que contribuem para a marginalização dos povos latino-americanos. Analisando os cenários de ditaduras e guerras civis, o autor os compreende como absurdos históricos determinados por grupos externos e que não trazem mudança em termos das melhorias de condições de vida para as maiorias populares. Os parcos processos revolucionários e de rebelião são vistos por ele como momentos de semiconsciência. Diante dessa realidade, não restaria perspectiva para as maiorias populares, a não ser a de aceitar a sua condição.

Contudo, a análise baroniana destaca sobremaneira uma faceta do fatalismo, qual seja, essa resignação e aceitação do estado das coisas contribui para a sua perpetuação. A despeito de sua relevância, tal aceitação tende a desconsiderar seu caráter dialético, enquanto expressão das próprias contradições do movimento do real, em que determinadas ações, 
mesmo podendo ser consideradas como conformadoras e resignadas, dialeticamente, constituem-se como protestos, como críticas, muitas das vezes inconscientes e individualizadas, das incongruências entre o indivíduo e a concretude social e histórica na qual se forja.

A partir do exposto, o presente artigo objetiva realizar um resgate crítico do conceito de fatalismo cunhado por Martín-Baró, à luz da realidade brasileira. Trata-se, ao mesmo tempo, de um retorno e atualização do que este autor denominou como fatalismo. Nesse processo, explicitaremos sua natureza dialética, a partir dos movimentos de resignação e revolta, em perspectivas individuais e/ou coletivas.

\section{Método}

Trata-se de uma pesquisa teórica, em que se analisa as produções de Martín-Baró que abordam o fatalismo tomando a realidade brasileira como parâmetro. Foram consultados livros do autor (físicos e digitais), bem como plataformas digitais que contêm sua produção ${ }^{1}$. O conceito é apresentado e desenvolvido em seu texto $O$ latino indolente: caráter ideológico do fatalismo latino-americano (Martín-Baró, 2017a), que serviu como obra principal de análise. Outras produções suas que também abordam o fatalismo (Martín-Baró, 1996; 2011; 2017b) foram analisadas. Não obstante, dialogamos também com a literatura secundária, possibilitando maior contextualização e esclarecimentos sobre o seu sentido. Para isso, realizamos uma busca no Google Scholar e contatamos especialistas na obra do autor, até chegarmos em dois trabalhos que analisaram especificamente o conceito de fatalismo em Martín-Baró, examinando-o histórica e epistemologicamente, e não apenas o descrevendo ou utilizando em suas análises: Blanco \& Díaz, 2007; Lacerda Júnior, 2014a.

Entendendo o fatalismo enquanto um conceito que enseja apreender determinados elementos da dinâmica do real, apenas o trabalho de análise teórica dos postulados baronianos seriam insuficientes; seria ficar no plano das ideias. É necessário que o conceito e seu escrutínio sejam defrontados com a realidade, entendendo que não se trata de qualquer realidade, mas a brasileira em suas especificidades. Para fazer isso, recorreremos a produções para a compreensão do processo de formação brasileiro (Coutinho, 1979; Ribeiro, 2006) e, nele, o fatalismo, bem como estudos que abordam elementos analisados por Martín-Baró para a formulação do conceito - ainda que não se debrucem sobre o autor -, como a crítica à cultura da pobreza (Patto, 1999; Zaluar, 2000), a relação dialética opressor-oprimido (Freire, 2005) e o sofrimento (Sawaia, 1999a; 1999b). Nesse interim, também traremos alguns dados sobre 
nossa realidade e produções artísticas nacionais, de cunho ilustrativo, no intuito de fornecer materialidade à discussão e exemplificar o fatalismo e sua dialética em nosso histórico.

Como forma de organização das ideias, o resultado de tal esforço analítico será apresentado, num primeiro momento, na dupla faceta de revolta e resignação do fatalismo e, posteriormente, no seu caráter individual e coletivo, mas entendendo que tal separação serve mais a fins didáticos. Ressaltamos que a concepção de dialética se refere ao método materialista histórico dialético, desenvolvido por Marx (Netto, 2011), conformando a análise. Finalmente, seguindo o exemplo de Martín-Baró, que analisava a realidade salvadorenha e latino-americana e traçava implicações à Psicologia e a seu projeto ético-político, a partir das reflexões sobre a dialética do fatalismo enquanto expressão de nossa realidade, refletiremos sobre como superá-lo, direcionando-o para a ordem social - como consta no título deste texto -, e ao papel da Psicologia. Tal como o autor, acreditamos que, dessa forma, seja possível e necessário não só compreender a realidade, mas contribuir para a sua transformação.

\section{Dialética do Fatalismo: entre a Revolta e a Resignação}

Segundo Lacerda Júnior (2014a), o fatalismo de Martín-Baró recebeu influência de três " $F$ ' $s$ ": Freire (Paulo), Fanon (Frantz) e Fromm (Erich). Tais fundamentações, segundo o autor, se devem provavelmente à importância da crítica da economia política desempenhada por Marx e sua consequente análise da sociabilidade capitalista, sem incorrer em determinadas interpretações que, apesar de se autodenominarem marxistas, tratavam de determinismos economicistas; bem como à necessidade de apreensão e teorização sobre a dialética subjetivo-objetivo. Sendo assim, Martín-Baró fundamenta-se no diálogo entre marxismo, psicanálise e outros referenciais críticos no âmbito da Psicologia e Ciências Sociais como um todo.

O fatalismo pode ser classificado como "comportamentos de conformismo e resignação diante de qualquer circunstância” (Martin-Baró, 2017a, p. 175) e é definido por três ideias: a de que a vida é predestinada, sem que as individualidades pesem no processo; a de que essa vida é definida por forças alheias; e a religião como um marco de referência, com a atribuição do destino a Deus. Contudo, não são meras abstrações, mas a internalização de uma realidade objetiva e suas relações sociais. Além disso, reverberam em sentimentos de resignação, aceitação do destino e de sofrimento, enquanto afetos aceitáveis, e em comportamentos de conformismo, submissão, passividade e presentismo. 
Entretanto, Martin-Baró (2017a) alerta que essa caracterização de fatalismo abre margem a um estereótipo do latino-americano que não necessariamente é real. Poucos são os estudos, teóricos ou empíricos, que tratam a temática. A maior parte assume o fatalismo como pressuposto. Os estudos que trabalham com autoimagem são os mais próximos de avaliarem a situação e demonstram que a forma como a pessoa se enxerga está associada às condições socioeconômicas locais. Ainda assim, a análise bibliográfica feita pelo autor lhe permite concluir que há traços do fatalismo latino-americano, observado principalmente nas parcelas populacionais pobres, em suas expressões cognitivas, comportamentais e afetivas.

De modo geral, podemos observar ressonância do fatalismo em vários elementos e dimensões de nossa realidade. Na música, por exemplo, nada mais explícito do que a canção "Deixa a Vida me Levar" (Silva, Meriti, \& Serafim, 2002), famosa na voz de Zeca Pagodinho, de onde só podemos agradecer a Deus pelo destino ofertado, deixando a vida nos levar, num movimento de aceitação pelo que se tem, mesmo que pouco ou quase nada.

Não obstante, é cabível supor que, com o recrudescimento de nossas desigualdades sociais e intensificação da precariedade da vida, o fatalismo também tende a ser aprofundado ou, ao menos, mais "requisitado" para o ocultamento e mistificação dessa realidade que, ao se deteriorar ainda mais, tende a tornar suas contradições mais evidentes. Por exemplo, como um sistema em que quase metade de toda a renda está concentrada nos $5 \%$ mais ricos da população e um quarto no $1 \%$ mais rico (Medeiros, Souza, \& Castro, 2015) se autossustenta, senão por meio de mecanismos como o fatalismo que contribuem para naturalizar esta realidade, oriundos e em determinação reflexiva com essa base constitutiva material? Ou um ordenamento social que, ao término de 2016, tinha 9,2\% de sua população em situação de extrema pobreza (Instituto Brasileiro de Geografia e Estatística, 2016)?

O fatalismo deve ser entendido, pois, a partir de sua utilidade para a manutenção de um sistema social, que tem como elemento nevrálgico a desigualdade (Martín-Baró, 2017a). É uma expressão da dominação social objetiva subjetivada, tendo a funcionalidade política de impossibilitar a mudança social. Isso porque os explorados e oprimidos aspiram, sim, por melhores condições de vida. Porém, os regimes sociais tratam de definir atitudes e comportamentos compatíveis ou não a eles. Ou seja, "mesmo sendo uma síndrome pessoal, representa um correlato psíquico de estruturas sociais determinadas" (Martin-Baró, 2017a, p. 191). O fatalismo adquire status de força natural e a-histórica e se converte em ideologia no sentido em que sua aceitação pelas classes oprimidas conduz à manutenção da ordem social. A associação com a religião, com um Deus situado fora da história, contribui ainda mais para isso. 
Não obstante, para entendermos a importância do fatalismo em nossa realidade, bem como dos embates e reflexões que evoca, é necessário compreendermos que ele possui um caráter dialético, em uma realidade contraditória. O próprio Martín-Baró (2017a) sinaliza tal caráter dialético, pois, ao mesmo tempo, pressupõe resignação e aceitação do estado das coisas como se fosse natural ou obra divina, mas havendo inúmeras erupções e tentativas de transformação da ordem no decorrer da história de nosso continente e de nosso país. Porém, Martín-Baró não aprofunda tal frente de análise, dando a entender que o fatalismo se refere apenas a uma resposta resignada ao sistema e que nele não pode haver uma faceta de contestação à ordem.

Ao caracterizar o fatalismo como "síndrome fatalista" (Martín-Baró, 2017a), o autor também abre brechas para interpretações psicologizantes e/ou que desconsiderem esse caráter dialético e dinâmico, ou seja, favorece uma psicologização da dinâmica social. Do mesmo modo, ao denominar o latino de "indolente”, também possibilita compreensões estáticas desse ser, na esteira dos tipos ideais weberianos, que historicamente acabaram por justificar nossa realidade, imputando a culpa aos indivíduos e a alguns de seus supostos atributos culturais rígidos (jeca-tatu, homem cordial, jeitinho brasileiro etc.). A análise da produção do autor e sua práxis evidenciam que esse não era seu intuito. Por isso, consideramos pertinente apontarmos suas possíveis contradições e realizar esclarecimentos que consideramos necessários.

Nesse sentido, sinalizamos que as respostas engendradas pelos indivíduos e grupos sociais, não somente as que pretendem modificar a ordem, mas também as que funcionam (ou são interpretadas) como aplacadoras, caracterizam-se como sinalizações de uma incongruência entre a essência do ser humano enquanto ser social e sua potência criativa imensurável e uma sociabilidade que o toma como indivíduo per si, o tolhe e o restringe. Conforme Marx (2013), um ser humano alienado e estranhado do fruto de seu trabalho, do seu próprio trabalho, do outro e de si, sendo, para isso, coisificado. Essa impossibilidade de potência, como já sinalizamos, é bem direcionada a determinada classe social e indivíduos: à classe trabalhadora e, nela, especialmente aos mais pobres.

No que tange à pobreza, existem estudos relacionados à "cultura da pobreza", que explicam o fatalismo como forma adaptativa a essa condição pauperizada, cujas raízes seriam psíquicas e, portanto, mais difíceis de serem modificadas. Contudo, o próprio Martín-Baró critica tal perspectiva por fazer entender que "o psíquico seria o fundamento da estruturação social e não o inverso. A incorporação ou não das pessoas ao sistema dependeria, portanto, de seus traços de caráter, não da natureza do sistema pessoal” (Martin-Baró, 2017a, p. 184). 
Zaluar (2000) aponta para os riscos de leituras pautadas em uma "cultura da pobreza", classificada geralmente como desagregada e sem consciência de classe e, por isso, sujeita ao populismo, ao clientelismo e ao fatalismo. O perigo de uma passagem imediata das condições materiais para as culturais gerou, principalmente em relação à diferenciação com a classe trabalhadora organizada, definições generalistas como as de passividade, atraso, apatia política e imediatismo, o que aponta para uma tensão entre objetividade e subjetividade. Tais visões implicam que tal população não seria capaz de se organizar e pensar autonomamente. Ou, como Patto (1999) sinaliza na crítica às "teorias da carência cultural", estaria à mercê de um destino pré-determinado, uma herança cultural que se reproduz e a priva de modificar sua própria condição de vida. A pergunta que permanece, então, é: “como poderiam, de fato, pessoas expostas a tal tipo de discriminação e exploração permanecer completamente dóceis ao sistema que as exclui e explora?" (Zaluar, 2000, p. 44). Tais leituras também desconsideram ou, pelo menos descaracterizam o que Paulo Freire apontou na dialética opressor-oprimido, com a aceitação e reprodução da opressão podendo advir também dos oprimidos ao se identificarem com os opressores (Freire, 2005).

Zaluar defende que os pobres não são "cegos diante da opacidade da estrutura" (Zaluar, 2000, p. 52). Há luta, reflexão e negociação e, por isso, a compreensão dos sistemas simbólicos também se faz importante para a percepção de que os pobres obviamente "pensam sobre o que lhes acontece e participam ativamente dos processos dos significados sociais. Se muitas vezes esse processo de pensamento permanece velado ou mesmo reprimido é porque não se ligaram os canais para ouvi-lo" (Zaluar, 2000, p. 57). Conforme apontam Mano Brown, Ice Blue e Edi Rock na música "Capítulo 4, Versículo 3" (1997), do disco Sobrevivendo no Inferno dos Racionais MC's, somos “violentamente pacífico[s]”.

Uma das formas de resistências à falta de um projeto alternativo de sociedade é identificada pela autora como a revolta, que se materializa de inúmeras formas. Para além das perspectivas de insurgência contra o sistema, por meio de processos revolucionários, existem outras formas de revolta atreladas principalmente com a criminalidade social. Nos contextos de pobreza há também o afastamento de modelos rígidos de moralidade a partir do momento em que se identifica o bandido como defensor do trabalhador em locais pouco visibilizados pelo Estado. Assim, a posição de "bandido", por exemplo, é relativizada, pois as condições de vida o aproximam do trabalhador, ao contrário da polícia, com quem não possuem tal identificação. Logo, há um conflito entre o orgulho de ser trabalhador e a consciência da exploração e opressão que os constitui e que, inclusive, justifica atitudes como o roubo (Zaluar, 2000). 
Não se trata, por outro lado, de romantizar a posição deste tipo de revolta, sobretudo no contexto capitalista, onde as concepções liberais de indivíduo e cidadão se dão pelo acesso ao consumo. Os ditos bandidos não são a priori

reformistas, nem revolucionários. Não necessariamente lutam por relações mais justas entre ricos e pobres, fortes e fracos. Suas ações podem ser interpretadas como uma revolta individual contra as condições adversas sob a forma de recusa ao trabalho destinado à população pobre” (Zaluar, 2000, p. 166).

O que há é uma identificação com o opressor, que não é exclusiva dos pobres, conforme observou Paulo Freire (2005). Dessa forma, a violência, enquanto uma das principais formas de revolta, surge de uma demanda material, mas também visa suprir a escassez de recursos simbólicos sem que, no entanto, vise a mudança social. Ao contrário, os discursos que permeiam a criminalidade legitimam, enquanto contrapartida social, processos mais duros de criminalização e repressão da pobreza. Além disso, este tipo de revolta acaba por secularizar a visão sobre a pobreza, não havendo uma espera passiva por saídas divinas ou do Estado.

Ademais, o capitalismo é sinônimo de crise. Ao gerar suas próprias contradições, produz as condições para a sua superação. Assim, conforme o próprio Martín-Baró (2017b) aponta, ao analisar o contexto de guerra civil em El Salvador, ao mesmo tempo em que as crises carecem de forjar fatalismo para se mistificarem, escancaram estas contradições, fornecendo oportunidades de rompimento com as amarras físicas e subjetivas, como o fatalismo. Devido a estes fatores, compreendemos que a revolta - em suas variadas possibilidades - e a resignação não podem ser demarcadas e dissociadas de maneira tão clara, mas sim compreendidas dialeticamente, coexistindo e se conformando. Por exemplo, sobre determinado assunto, observamos posturas mais contemplativas de uma pessoa, grupo ou coletividades, sendo que, em outros, ocorrem perspectivas mais irascíveis; igualmente, ambas manifestações podem ser vistas concomitantemente; por fim, existem casos em que a passagem de uma para outra se dá de maneira abrupta e/ou inconsciente atrelada às condições de vida. Como aponta Martín-Baró, em diálogo com Fanon: "[a] semente da rebeldia, de recusa a um destino injusto, não necessita ser semeada; encontra-se no espírito do colonizado e demanda apenas encontrar uma circunstância propícia para brotar" (Martín-Baró, 2017a, p. 197). 


\section{Dialética do Fatalismo: o Individual e o Coletivo e a Fatalização das Maiorias Populares}

A partir do exposto, compreendemos que a dialética do fatalismo denota, em nossa história, ambas as possibilidades de resposta, de revolta ou de resignação, que tiveram e têm, em grande parte, como fim a fatalidade de seus indivíduos, sobretudo os da classe trabalhadora. E essa fatalização se dá física e/ou subjetivamente, conforme são compreendidas e respondidas pelo Estado, instituições e sociedade. Portanto, é importante deixar claro que não é o fatalismo atribuído às maiorias populares, sobretudo aos trabalhadores pobres, o responsável por sua posição social, sendo fundamental focalizar nas estruturas sociais e nas relações de poder que mantêm a desigualdade, bem como nas privações reais que, por consequência, geram situações de fatalismo; são internalizações e subjetivações de uma realidade objetiva e externa (Martín-Baró, 2011; 2017a). Consequentemente, cabe questionar como transformar esse fatalismo das maiorias populares para o da ordem, entendendo que a transformação social radical se faz objetiva e subjetivamente. No entanto, primeiramente, precisamos compreendê-lo.

Com relação à fatalidade física das maiorias populares, o que se viu historicamente no processo de desenvolvimento do país - e da América Latina como um todo - foram estratégias de controle social, segregação, criminalização ou de extermínio e genocídio de determinados indivíduos e grupos sociais que intentaram insurgir contra o sistema e se libertar. Atreladas a estas estratégias explícitas de violência e repressão, outras formas de manutenção da ordem e fatalização das maiorias populares também engendraram nossa realidade, só que por vias da conciliação e concertação social, o que Coutinho (1979) denominou de reformismo "pelo alto", pautado pela necessidade de conservação da ordem, mesmo que afetado pelas lutas sociais e tensionamentos de grupos explorados e oprimidos. Conforme Darcy Ribeiro (2006, p. 408), o que houve e há neste país “é uma massa de trabalhadores explorada, humilhada e ofendida por uma minoria dominante, espantosamente eficaz na formulação e manutenção de seu próprio projeto de prosperidade, sempre pronta a esmagar qualquer ameaça de reforma da ordem social vigente". Manutenção que se deu de maneira abrupta, por meio da repressão e força bruta ou por processos mais sutis e apaziguadores e, portanto, mais difíceis de serem percebidos e fáceis de serem naturalizados; daí a importância de se considerar o fatalismo como um desses mecanismos.

Se as estratégias de revolta foram reprimidas ou aplacadas no Brasil e América Latina em geral, a resignação também não forneceu frutos muito diferentes. Na manutenção da ordem supracitada, observamos o desvelamento de outras formas de controle e sofrimento, 
como os índices cada vez mais crescentes de transtornos mentais, determinadas doenças, suicídios, dentre outros, tendo como alvos preferenciais a classe trabalhadora e, nela, aqueles indivíduos e grupos sociais mais subalternizados, como mulheres, negro(as), pobres, periféricos etc. Não à toa, os maiores índices de ocorrência de transtornos mentais, como ansiedade e depressão, bem como os piores indicadores de bem-estar psicológico e autoestima se dão na população negra (Faro \& Pereira, 2011). No que tange à questão de gênero, existe uma maior prevalência destes transtornos em mulheres, juntamente com outros determinantes, como condição de desemprego, baixa escolaridade e renda (Gonçalves et al., 2014). Inclusive, a partir destas constatações, compreendemos alguns dos porquês de a medicalização ascender enquanto forma sofisticada de docilização e silenciamento em nossa sociedade.

Portanto, cabe a reflexão de que, apesar destes sofrimentos serem reverberações de resignações e silenciamentos, por outro lado, podem ser uma forma - talvez a única possível de resposta e de visibilidade à exploração e opressão. Logo, ao invés de serem compreendidos como doenças, questões em si, de cunho individual, biopsicológicas, também podem ser entendidos como "revoltas" silenciosas ou silenciadas, sintomas de nossa sociabilidade. Não por acaso, essa perspectiva se volta principalmente para tais indivíduos e grupos sociais que compõem o grosso da classe trabalhadora. Isso se deve ao fato de que, ao sofrerem na pele de forma mais venal as barbaridades de nossa sociabilidade, passam a carregar consigo grande potencial revolucionário - remetendo à Martín-Baró (2017a), portam as sementes da recusa ao destino injusto; afinal, nada (ou pouco) têm a perder, exceto seus grilhões.

Consonante ao fatalismo físico das maiorias populares em nosso país, também se verifica a morte ou fatalidade subjetiva, por meio de processos de assujeitamento destes indivíduos que, ao serem concebidos e tratados como subalternos, cidadãos de segunda classe etc., tornam-se não-humanos. A partir das sinalizações de Lacerda Júnior (2014b), entendemos que o isolamento, fomentado pela sobreposição da individualidade e da competitividade à coletividade e à solidariedade, e a vulnerabilidade - material (a expropriação) e subjetiva -, são formas de sofrimento humano inerentes ao capitalismo, caracterizando-se como um de seus produtos e se fortalecendo, ao mesmo tempo em que perpetuam essa sociabilidade. Isso se encontra na esteira do que Sawaia (1999a) nomeou de sofrimento ético-político, isto é, as implicações subjetivas da vivência cotidiana da desigualdade social, as restrições do potencial de ação humano por uma ordem social que nos aliena e espolia de nossas próprias produções, materializada nas relações que estabelecemos, nos espaços públicos que percorremos, nas formas como nos vemos e concebemos e nos afetos que somos impedidos de expressar. 
O sofrimento ético-político deve ser compreendido, então, a partir da dialética exclusão/inclusão como forma de superação da concepção de neutralidade, da legitimação da opressão e da culpabilização do indivíduo por sua situação social. Assentar-nos-emos em tal dialética, compreendendo que não há exclusão na sociabilidade capitalista; afinal, cada um de nós está incluído nela, de formas variadas, que se referem à classe a que pertencemos e como essa se organiza e reifica nas e pelas estruturas raciais (e racistas), patriarcais (e machistas), dentre outras. Conforme sinalizado, existe um caráter estrutural da pobreza no âmbito do capitalismo, como expressão de sua contradição-mor capital-trabalho, e consequentes funcionalidades. É nesse sentido que tomamos as observações de Sawaia (1999b) sobre a existência de uma "inclusão" que, por conta destes fatores, se torna perversa, enquanto estratégia para manutenção da ordem social, sem que a desigualdade inerente de nossa sociabilidade seja tratada. Esta "inclusão perversa", por sua vez, é alimentada nos e pelos indivíduos, afastando-os de possibilidades coletivas (Sawaia, 1999b). O sofrimento éticopolítico se dá na cisão entre pensar, agir e sentir e só é possível em uma sociedade em conflito oriundo da luta de classes. Portanto, não é algo meramente individual, mas determinado pela situação social e pela impossibilidade de superação frente à desigualdade.

Tal sofrimento é expresso, por exemplo, por Gilberto Gil e Dominguinhos em seu "Lamento Sertanejo" (1975), sintetizando as agruras de boa parte dos retirantes nordestinos, compelidos à vida famélica na cidade grande, na esperança ou obrigatoriedade de prover seu sustento e de suas famílias. Um choque de costumes e sentimentos, oriundos das contradições entre o campo e a urbe, impondo o segundo como possibilidade e padrão de vida que se materializam nos e pelos indivíduos; indivíduos que, por isso, quase não saem, não falam, quase não têm amigos e não sabem de nada, se sentindo como reses desgarradas, não pertencentes, numa multidão/boiada que, por sua vez, marcha sem saber para onde e porquê. Na literatura, Carolina de Jesus, com seu "Quarto de Despejo" (1963) e o constante "nervoso interior", as indisposições e aborrecimentos, em que, apesar da vida atribulada que levava de mãe, trabalhadora precária, negra, pobre e periférica, sempre estava em falta; uma catadora de papel e lixo que só não catava felicidade; um rebotalho, como ela mesmo se via, à espera de ser queimada ou jogada no lixo. Conforme mencionado, a alusão a tais produções não significa uma análise sobre o fatalismo nas artes, o que empreenderia um esforço mais robusto, mas demonstrar ilustrativamente a sua existência e conformação em nossa realidade.

São inúmeros os exemplos da presença do sofrimento ético-político, atrelado ao caráter desigual e de injustiça de nossa sociabilidade (Sawaia, 1999b), bem como de sua explicitação na arte e cultura, como manifestações desta realidade. Obviamente que estes 
fenômenos se expressarão e serão respondidos de diferentes formas nos e pelos indivíduos, grupos e classes, por terem natureza multideterminada, mediadas pelas particularidades que cimentam a vida social e irão concretizar elementos da totalidade social nas singularidades destes seres. Seres plurais, totalidades múltiplas, cujas singularidades se fazem em uma determinada sociabilidade e, portanto, a expressam, juntamente com a própria universalidade do ser humano enquanto ser social. Nessa dialética singular-particular-universal, vamos nos produzindo processualmente na e pela ação, ao passo que modificamos a realidade à nossa volta, damos sentido a ela e a nós mesmos (Pasqualini \& Martins, 2015).

Logo, o caráter dialético do fatalismo também se desvela nas possibilidades de manifestações individuais e coletivas. Blanco e Diaz (2007) atentaram para isso no que denominaram de o "rosto de duas caras" do fatalismo, coletivo e individual. Porém, em nossa análise, os autores desconsideraram outra "dupla faceta" desse rosto: a resignação-revolta, conforme explicitamos anteriormente. Na trilha de Martín-Baró, tomaram apenas a resignação em suas possibilidades coletiva e individual. Ao mesmo tempo em que uma atitude submissa atrelada a um suposto destino pronto é manifestação adaptativa à vida em uma sociedade cada vez mais incerta e insegura, ela também expressa a própria miséria dessa realidade que carece de posturas como essa para se manter.

Tal caráter dialético, que perpassa as manifestações dos indivíduos frente às suas realidades, remete à problematização feita por Marx (2010a) acerca da religião na Crítica da Filosofia do Direito de Hegel - Introdução. Segundo o próprio "[a] miséria religiosa constitui ao mesmo tempo a expressão da miséria real e o protesto contra a miséria real" (p. 145). Assim, o fatalismo é, dialeticamente, a expressão da miséria real e o protesto contra ela. A análise crítica do fatalismo supõe a análise crítica radical da sociedade que produz o fatalismo. Romper com o fatalismo que se volta aos indivíduos, significa fatalizar a ordem que o produz e necessita dele para se manter, a ordem que é fatalista; isto é, transformá-la radicalmente. Veremos, a seguir, as implicações à Psicologia brasileira nesse processo.

\section{A Ruptura com o Fatalismo: Implicações para a Psicologia Brasileira}

A partir dessa compreensão do fatalismo como a dialética entre a resignação e a revolta, de nível individual e coletivo, mas que fataliza/extermina (física e/ou subjetivamente) os próprios indivíduos, as questões que se colocam são: Como transformá-lo, de modo que contribua para a fatalização - supressão - da ordem social e não dos indivíduos? E como a Psicologia pode contribuir para isso? 
O próprio Martín-Baró (1996; 2017a) já nos sinalizava alguns caminhos para a superação do fatalismo, o que para nós implica em direcioná-lo à ordem, como: (1) a recuperação da memória histórica e a superação do presentismo; (2) a organização popular; e (3) uma prática de classe. Em diálogo com o autor, adicionamos: (4) a necessidade de fortalecer as condições objetivas comunitárias e, (5) a conscientização enquanto horizonte do quefazer psi. Cabe ressaltar que, a despeito de focalizarmos na Psicologia, tais princípios não se restringem a ela.

No que diz respeito ao fortalecimento das condições de vida concretas, intervenções comunitárias podem contribuir para minimizar o sofrimento ético-político e o fatalismo, concebendo os próprios indivíduos como políticos, e que podem e devem se indignar, resistir e se comprometer socialmente. Todavia, compreendemos as limitações destas ações, pois as possibilidades de ruptura do fatalismo pressupõem mudanças sociais, que estão ligadas dialeticamente, possíveis a partir de movimentos de conscientização que, por sua vez, só são viáveis a partir do conhecimento de suas origens e de sua história (Martín-Baró, 1996; 2011).

Assim, a ruptura do fatalismo "requer uma mudança revolucionária, isto é, uma mudança nas estruturas políticas e econômicas e, também, psicossociais" (Martín-Baró, 2017a, p. 199). Portanto, nos aproximamos de Marx (2010b), tomando como horizonte a emancipação humana numa pauta anticapitalista - em nosso caso, na supressão necessária de nossas especificidades coloniais, periféricas e dependentes -, compreendendo os progressos, mas também as limitações da dimensão política e da emancipação que ela pode proporcionar no capitalismo por meio de políticas sociais, garantia de direitos, sociais, políticos e civis etc. Contudo, é importante considerar que, por mais que seja limitada, a expansão dessas mudanças no âmbito político pode incidir nas bases materiais/estruturais de nossa sociabilidade. Afinal, não é à toa que as medidas neoliberais se voltam para vilipendiar ainda mais as políticas sociais no contexto brasileiro atual, sendo perpassadas por inúmeros cortes e retrocessos.

É possível pensar em conexões entre a emancipação política e a humana, não num sentido de passagem gradativa de uma para outra, por meio de um acúmulo da primeira, mas como a expansão de direitos que, além de suprir necessidades imediatas de parcelas da população necessitadas, pode contribuir para tensionar o estado das coisas, desvelando as contradições de nossa sociabilidade. Dessa forma, por mais que não seja esta uma luta estratégia revolucionária, ela pode corroborar para processos revolucionários, sendo sua defesa parte de um projeto anticapitalista (Souza Filho, 2016). 
Não obstante, da mesma forma que se pode aprofundar o caráter conformista do fatalismo com a intensificação da desigualdade social, também é possível que se apresentem oportunidades de escancarar as incongruências de nossa ordem e suscitar movimentos de fissura. Por exemplo: segundo dados do Departamento Intersindical de Estatística e Estudos Socioecônomicos (DIEESE), entre os anos de 2012 e 2013 o número total de greves no país aumentou cerca de 234\%, com um total de 2050 movimento grevistas em 2013, número este que se manteve próximo em 2016, com 2093 greves. Porém, um dado é especialmente relevante: se em 2013 o caráter das greves era equilibrado entre as propositivas e as defensivas, em 2016 cerca de 1694 greves foram consideradas defensivas, ou seja, visando a manutenção de direitos (DIEESE, 2015; DIEESE 2017), evidenciando uma ofensiva do capital à classe trabalhadora, culminando em estratégias defensivas ao invés de insurgentes.

A partir disso, como (re)pensar os fundamentos da Psicologia brasileira, levando em consideração a dialética do fatalismo que conforma os indivíduos e a realidade? Ou mais, como refletir sobre a própria Psicologia se, como define Martin-Baró (1996), esta proliferou em nosso contexto enquanto ideologia de reconversão, apresentando como solução a mudança e adequação do indivíduo frente à manutenção da ordem social? De forma sintética, em função das limitações de espaço, discorreremos sobre as implicações da dialética do fatalismo - como tentativa de apreensão do movimento do real em nossa sociedade - para a Psicologia brasileira, no que diz respeito aos seus fundamentos e pressupostos.

Uma primeira reverberação diz respeito à necessidade de crítica a leituras que tratam o brasileiro como passivo ou acomodado e a sua desconsideração das inúmeras manifestações existentes que não se dão por meio da revolta ou irrupção explícitas, vistas como não-atos, ou expressões silenciosas e, que, até mesmo, podem passar despercebidas por se autoexplicarem ou estarem vinculadas a questões de ordem individual biológicas ou psicológicas. Por outro lado, observamos tradições sociológicas também personalistas e culturalistas que concebem o brasileiro como malandro ou matreiro quando se comporta de modo a questionar e romper com o que está posto, numa concepção da identidade social do brasileiro como movido pelo interesse próprio e por um suposto jeitinho, exclusivo de nossa constituição e de mais ninguém. Na verdade, o que essas interpretações fazem é desvelar seu caráter ideológico e funcionalidade à manutenção da ordem, ao invés de captarem a multiplicidade de respostas humanas à sociedade que as engendra e que elas também produzem, sob condições que não as suas. Segundo Martín-Baró (2017a), são fatalistas, no sentido de contribuírem à manutenção da ordem. Iasi (2013), ao confrontar interpretações de que a classe trabalhadora, sobretudo a brasileira, seja ontologicamente reformista, isto é, acomodada à ordem, ou revolucionária, e as 
relações entre essa posição e os processos de desenvolvimento de uma consciência de classe, esclarece esse caráter dialético:

Estas manifestações são expressões do ser da classe trabalhadora, ou seja, a classe trabalhadora é ao mesmo tempo uma classe da ordem do capital, e por isso expressa na sua consciência os elementos do amoldamento e, exatamente por ser uma classe da ordem do capital, pode entrar em choque com esta ordem almejando ir além dela e, quando o faz, expressa uma consciência que pode chegar a uma consciência de classe (Iasi, 2013, pp. 74).

Embebida numa lógica liberal, inerente à sociabilidade em que surge e a expressa, a Psicologia ainda é perpassada por concepções de indivíduos que se autoproduzem e reproduzem, ou mesmo produtos estáticos e prontos, frutos de seus aparelhos psíquicos e estruturas psicológicas (por exemplo, o conceito de personalidade rígida, imutável), ou de um ser visto de maneira passiva, guiado por "forças" interiores que não pode controlar ou modificar. Isso nos leva a um determinismo psicológico que corrobora para processos de individualização das interpretações, assim como a reificação deste ser humano, junto com a naturalização de suas condições de vida. Processo que designamos como "Síndrome de Gabriela", em referência à música "Modinha para Gabriela", de Dorival Caymmi (1975) e famosa na voz de Gal Costa: "Eu nasci assim, eu cresci assim; Eu sou mesmo assim; Vou ser sempre assim; Gabriela, sempre Gabriela".

Nesse sentido, cabe a nós questionarmos o papel da Psicologia e outros campos do saber e de práticas e seu caráter fatalizante ao abordar o ser humano e as dimensões e fenômenos que o perpassam e constituem, muitas das vezes, de maneira parcializada, estática e autocentrada. Ou seja, em que sentido a Psicologia e suas leituras sobre o ser humano e a realidade também não contribuem para o aguçamento deste fatalismo, por meio de leituras e ações individualizantes, docilizantes, patologizantes, normatizantes e ajustadoras? Afinal, ao empreendermos análises sobre a Psicologia, não devemos dissociá-la da sociabilidade na qual surge e se desenvolve - em nosso caso específico, a brasileira e latino-americana -, compreendendo-a enquanto produto/expressão da sociabilidade na qual se forja, ao passo que também contribui para a sua conformação.

Logo, o horizonte ético da Psicologia latino-americana deve ser o da libertação de seus povos e o comprometimento com sua realidade. A reformulação do conceito de consciência, então, se faz fundamental para compreender a conscientização, horizonte do quefazer do 
psicólogo, segundo o próprio Martín-Baró (1996), que deve ser tida como o saber sobre si e sobre o mundo e partir de três pressupostos: a concepção dialética de que o ser humano se modifica ao transformar sua realidade; com a desnaturalização e decodificação do mundo há novas possibilidades de ação; a nova concepção de mundo conduz a uma nova visão de si. O processo de conscientização contribui com respostas à injustiça social a partir de suas raízes (objetivas e/ou subjetivas) e visa, ainda, a recuperação de memória histórica e a superação do presentismo - outros pontos apontados por Martín-Baró para a superação do fatalismo - e a supressão das categorias de opressores e oprimidos (Martin-Baró, 1996). Ao visar transformar as condições objetivas e subjetivas comunitárias e das classes, entende-se que estas não são opostas ou dicotômicas, da mesma forma que a tomada de consciência individual e coletiva afinal, o comunitário se expressa justamente na capacidade de se responder às necessidades individuais sem que exista uma contradição com o coletivo.

Ainda, o horizonte da libertação é instrumento para o outro ponto fundamental na superação do fatalismo elencado por Martín-Baró, (2011): o fortalecimento da organização popular, indo além da esfera política e do aparato estatal - apesar da necessidade de sua utilização e disputa, inclusive, para o atendimento de necessidades básicas emergenciais. Nesse ponto, cabe também ao psicólogo compreender-se enquanto classe trabalhadora, se inserindo e atuando em/com movimentos sociais e políticos, compreendendo que não é ele o ator estritamente revolucionário, mas que, enquanto trabalhador, pode contribuir por meio de processos de desideologização, conscientização, juntamente com sua atividade política, para o fortalecimento de indivíduos, grupos e melhorias de suas condições de vida, desvelando as contradições dessa sociabilidade, para que ela seja, assim, superada.

\section{Considerações Finais}

A construção deste trabalho parte da análise do contexto de extrema desigualdade e fragmentação social da realidade latino-americana e, nela, a brasileira, para refletir sobre a dialética fatalista, contribuindo para a compreensão e superação de nossa ordem social. Realizamos, pois, um resgate crítico do conceito de fatalismo de Martin-Baró, definido como destino fatal que marginaliza os povos latino-americanos de suas próprias histórias por meio de uma aceitação passiva e resignada de sua condição. No entanto, é fundamental ressaltar que a resignação ou o fatalismo não são fenômenos naturais e individuais, pois, ao mesmo tempo, expressam uma incongruência entre estes seres e suas realidades. Logo, só podem ser compreendidos enquanto construções históricas, oriundas de nossas bases constitutivas 
enquanto país. É necessário, assim, compreender que a subserviência econômico-política na qual foi colonizada a América Latina também se manifesta nas subjetividades, porém, não num determinismo mecanicista.

Nota-se que os processos de resistência e revolta, presentes na dialética do fatalismo, mesmo que em caráter individualista ou coletivo, não têm sido capazes de alcançarem caráter insurgente e de ruptura da ordem, enquanto as respostas institucionais se voltam contra esses indivíduos em forma de extermínio, criminalização ou mais apassivamento. Ou seja, em forma de um silenciamento concreto e subjetivo que provoca o retorno ao fatalismo - em um movimento de repetição sem o surgimento de uma síntese que expresse o novo. Dessa forma, a revolta e a resignação operam como manutenção dos quadros exploratórios e opressivos, inclusive nas definições de doença, saúde e saúde mental, por exemplo.

Para a Psicologia brasileira, a compreensão desta dialética implica na necessidade de uma leitura crítica sobre as teorias que naturalizam nossa realidade, bem como sua visão fatalista e o recorrente determinismo psicológico, de modo a não ser meio de mais normatização e docilização. Elencamos e discorremos, neste quadro, algumas possibilidades de passagem de um fatalismo dos indivíduos para o fatalismo da ordem, seja a partir das contribuições da Psicologia, seja enquanto visão de mundo geral que perpassa a todos: 1) a recuperação da memória histórica; 2) o fortalecimento da organização popular, sobretudo em formas não-estatais; 3) compreensão de si e atuação enquanto classe trabalhadora; 4) fortalecimento das condições objetivas comunitárias e 5) conscientização enquanto horizonte do quefazer psi.

\section{Referências}

Blanco, A., \& Díaz, D. (2007). El rostro bifronte del fatalismo: Fatalismo colectivista y fatalismo individualista. Psicothema, 19(4), 552-558. Recuperado de http://www.psicothema.com/pdf/3396.pdf

Brown, M., Blue, I., \& Rock, E. (1997). Capítulo 4, Versículo 3 (Gravada por Racionais MCs). Sobrevivendo no inferno [CD]. São Paulo: Cosa Nostra.

Caymmi, D. (1975). Modinha para Gabriela (Gravada por Gal Costa). Gabriela: Trilha sonora original [CD]. Rio de Janeiro: Som Livre.

Coutinho, C. N. (1979). A democracia como valor universal. Encontros com a Civilização Brasileira, $9, \quad 33-48 . \quad$ Recuperado de https://www.marxists.org/portugues/coutinho/1979/mes/democracia.htm 
DIEESE. (2017). Balanço das greves em 2016. Estudos e Pesquisas, (84), 2-35. Recuperado de https://www.dieese.org.br/balancodasgreves/2016/estPesq84balancogreves2016.html

DIEESE. (2015). Balanço das greves em 2013. Estudos e Pesquisas, (79), 2-44. Recuperado de https://www.dieese.org.br/balancodasgreves/2013/estPesq79balancogreves2013.pdf

Faro, A., \& Pereira, M. E. (2011). Raça, racismo e saúde: A desigualdade social da distribuição do estresse. Estudos de Psicologia, 16(3), 271-278. doi:10.1590/S1413294X2011000300009

Freire, P. (2005). Pedagogia do Oprimido. Rio de Janeiro: Paz e Terra.

Gil, G., \& Morais, J. D. (1975). Lamento sertanejo (Gravada por Gilberto Gil). Refazenda [CD]. Rio de Janeiro: Warner Music Brasil.

Gonçalves, D. A., Mari, J. J., Bower, P., Gask, L., Dowrick, C., Tófoli, L. F., Campos, M., Portugal F. B., Ballester, D., \& Fortes, S. (2014). Brazilian multicentre study of common mental disorders in primary care: Rates and related social and demographic factors. Cadernos de Saúde Pública, 30(3), 623-632. doi:10.1590/0102$311 \mathrm{X} 00158412$

Iasi, M. L. (2013). Educação e consciência de classe: Desafios estratégicos. Perspectiva, 31(1), 67-83. doi:10.5007/2175-795X.2013v31n1p67

Instituto Brasileiro de Geografia e Estatística [IBGE]. (2016). Síntese de indicadores sociais: Uma análise das condições de vida da população brasileira. Rio de Janeiro: IBGE. Recuperado de https://biblioteca.ibge.gov.br/visualizacao/livros/liv101629.pdf

Jesus, C. M. (1963). Quarto de Despejo. São Paulo: Edição Popular.

Lacerda Júnior, F. (2014a). Fatalism, Overview. In T. Teo (Org.), Encyclopedia of Critical Psychology (pp. 690-693). New York: Springer.

Lacerda Júnior, F. (2014b). Psicologia Política e marxismo na história recente: Contribuições de Martín-Baró e Holzkamp. In S. A. M. Sandoval, D. U. Hur, \& B. S. A. Dantas (Orgs.), Psicologia Política: Temas atuais de investigação (pp. 25-52). Campinas: Alínea.

Martin-Baró, I. (2017a). O latino indolente: Caráter ideológico do fatalismo latino-americano. In F. Lacerda Júnior (Org.), Crítica e Libertação na Psicologia (pp. 173-203). Petrópolis: Vozes.

Martín-Baró, I. (2017b). Guerra e Saúde Mental. In F. Lacerda Júnior (Org.), Crítica e libertação na Psicologia: Estudos psicossociais (pp. 251-270). Petrópolis: Vozes. 
Martín-Baró, I. (2011). Para uma psicologia da libertação (Fernando Lacerda Jr., Trad.). In R. S. L. Guzzo, \& F. Lacerda Jr. (Orgs.), Psicologia social para América Latina: O resgate da psicologia da libertação (pp. 101-120). Campinas: Alínea.

Martin-Baró, I. (1996). O papel do psicólogo. Estudos de Psicologia, 2(1), 7-27. Recuperado de http://www.scielo.br/pdf/epsic/v2n1/a02v2n1.pdf

Marx, K. (2013). O Capital: Crítica da economia política: Livro 1: O processo de produção do capital. São Paulo: Boitempo.

Marx, K. (2010a). Crítica da filosofia do direito de Hegel. São Paulo: Boitempo.

Marx, K. (2010b). Sobre a questão judaica. São Paulo: Boitempo.

Medeiros, M., Souza, P. H. G. F., \& Castro, F. A. (2015). A estabilidade da desigualdade de renda no Brasil, 2006 a 2012: Estimativa com dados do imposto de renda e pesquisas domiciliares. Cienência \& Saude Coletiva, 20(4), 971-986. doi:10.1590/141381232015204.00362014.

Netto, J. P. (2011). Introdução ao estudo do método de Marx. São Paulo: Expressão Popular.

Pasqualini, J. C., \& Martins, L. M. (2015). Dialética singular-particular-universal: Implicações do método materialista dialético para a psicologia. Psicologia \& Sociedade, 27(2), 362-371. doi:10.1590/1807-03102015v27n2p362

Patto, M. H. S. (1999). A produção do fracasso escolar: Histórias de submissão e rebeldia. São Paulo: T. A. Queiroz.

Ribeiro, D. (2006). O povo brasileiro: A formação e o sentido do Brasil. São Paulo: Cia das Letras.

Sawaia, B. (1999a). O sofrimento ético-político como categoria de análise da dialética exclusão/inclusão. In B. Sawaia (Org.), As artimanhas da exclusão: Análise psicossocial e ética da desigualdade social (pp. 97-118). Petrópolis: Vozes.

Sawaia, B. (1999b). Introdução: Exclusão ou inclusão perversa? In B. Sawaia (Org.), As artimanhas da exclusão: Análise psicossocial e ética da desigualdade social (pp. 715). Petrópolis: Vozes.

Silva, E. S., Meriti, S., \& Serafim, S. R. (2002). Deixa a vida me levar (Gravada por Zeca Pagodinho). Deixa a vida me levar [CD]. Rio de Janeiro: Universal Music.

Souza Filho, R. (2016). Fundo público e políticas sociais no capitalismo: Considerações teóricas. Revista Serviço Social e Sociedade, (126), 318-339. doi:10.1590/01016628.071 
Yamamoto, O. H., \& Oliveira, I. F. (2010). Política Social e Psicologia: Uma trajetória de 25 anos. Psicologia: Teoria e Pesquisa, 26(n. esp.), 9-24. doi:10.1590/S010237722010000500002

Zaluar, A. (2000). A máquina e a revolta: as organizações populares e o significado da pobreza. São Paulo: Brasiliense.

\section{Endereço para correspondência}

\section{Pedro Henrique Antunes da Costa}

CLN 407, Bloco E, 51, apartamento 204, Asa Norte, Brasília - DF, Brasil. CEP 78055-550

Endereço eletrônico: phantunes.costa@gmail.com

\section{Kíssila Teixeira Mendes}

Rua Doutor João Pinheiro, 282/305, Jardim Glória, Juiz de Fora - MG, Brasil. CEP 36015-040

Endereço eletrônico: kissilamm@ hotmail.com

Recebido em: 30/10/2019

Reformulado em: 10/05/2020

Aceito em: 31/05/2020

\section{Notas}

* Psicólogo, Mestre e Doutor em Psicologia pela Universidade Federal de Juiz de Fora (UFJF). Professor do Instituto de Psicologia da Universidade de Brasília.

** Psicóloga e Cientista Social; Mestre e Doutoranda em Psicologia pela UFJF.

1 Cátedra Libre Martín-Baró (http://www.catedralibremartinbaro.org/html/imbdescargas.php); e Colección Digital Ignacio Martín-Baró, da Universidad Centroamericana José Simeón Cañas (http://www.uca.edu.sv/coleccion-digital-IMB/)

Agradecimentos: Os autores agradecem a Fernando Lacerda Júnior pela revisão do manuscrito.

Este artigo de revista Estudos e Pesquisas em Psicologia é licenciado sob uma Licença Creative Commons Atribuição-Não Comercial 3.0 Não Adaptada. 